\title{
"LA PALABRA ES DE USTEDES, ME CALLO POR PUDOR": ANTIINTELECTUALISMO Y EMERGENCIA DEL TESTIMONIO EN CUBA
}

\author{
"THE WORD BELONGS TO YOU, I AM SILENT BECAUSE \\ OF MY MODESTY": ANTI-INTELLECTUALISM AND THE \\ EMERGENCE OF TESTIMONY IN CUBA
}

\section{JAUME PERIS BLANES ${ }^{1}$}

\section{RESUMEN}

El artículo señala y analiza la presencia del testimonio como función no conceptualizada en los debates sobre el papel del intelectual revolucionario en la Cuba de los años sesenta. Algunas canciones de la Nueva Trova Cubana aludían explícitamente a la enunciación testimonial como una forma de superar el descrédito que la voz intelectual había sufrido en esos debates, ligando la emergencia del testimonio al auge del antiintelectualismo. Esa relación se hallaba ya presente, como demuestra el artículo, en los textos de Castro o Guevara, y continuaría estándolo en la instauración del premio testimonio de Casa de las Américas en 1970.

Palabras clave: Testimonio, antiintelectualismo, Revolución Cubana, Silvio Rodríguez.

\section{ABSTRACT}

The author shows and analyzes the presence of testimony as a non-conceptualised function in the cultural debates about the role of intelligentsia in Cuban Revolution. Some songs of the Nueva Trova Cubana refered to testimonio as a way for overcoming the difficulties of these debates and linked the emergence of testimonio to the rise of 'antiintelectual' imagination. This relationship was already present, as the article aims to show, in the texts written by Castro or Guevara and in the main discourses which accompanied the creation of the testimonio prize by Casa de las Américas.

Keywords: Testimony, antiintelectualism, Cuban Revolution, Silvio Rodríguez.

Recibido: 03.12.12. Aceptado: 14.09.13.

${ }^{1}$ Dr. en Filología. Profesor del Departamento de Filología Española en la Universitat de Valencia.Valencia, España. E-mail: jaume.peris@uv.es 


\section{INTRODUCCIÓN}

N LA SEgUnda MitAD de los años sesenta, y como efecto de la polémica cultural sobre la función del intelectual de izquierdas, tuvo lugar en Cuba la emergencia de un imaginario 'antiintelectualista' (Gilman, 2003) en el que las competencias específicas del intelectual sufrieron un importante proceso de descrédito. En ese contexto, buena parte de la producción cultural cubana, desde las canciones de la Nueva Trova hasta las novelas del nuevo realismo o la poesía comunicante de la época, se hizo eco de la problemática del intelectual y construyó relatos, imágenes poéticas y argumentaciones que aludían a la contradictoria situación de los intelectuales y a los impasses y dificultades de la cultura revolucionaria.

Entre todas esas intervenciones culturales, dos textos de Silvio Rodríguez ("Canción para la Columna Juvenil del Centenario" canción compuesta y cantada a dúo con Pablo Milanés [1967] y "Playa Girón” [1969]), exponente mayor de la Nueva Trova Cubana, aludían directamente al impasse al que se enfrentaba la producción intelectual del momento y proponían una salida al conflicto cultural que, aunque sin nombrarlo, apuntaba al testimonio como eje de la nueva cultura revolucionaria.

La hipótesis de este artículo es que esa 'solución' aparecía ya, aunque de un modo implícito y carente de conceptualización, en las intervenciones mayores del debate sobre la función del intelectual de los años anteriores y, especialmente, en las intervenciones de los líderes revolucionarios (Fidel Castro y Che Guevara) en que ponían límites a la actividad de los intelectuales liberales ligados a la Revolución. Aunque de un modo poco definido, continuaría sobrevolando los discursos culturales cubanos hasta la instauración del premio testimonio de Casa de las Américas en 1970, que dio cobertura institucional a numerosas textualidades que hasta entonces habían quedado fuera de las categorizaciones literarias.

Para desarrollar esa hipótesis, el autor se valdrá del análisis textual de los citados textos de Rodríguez, de los discursos sobre la función del intelectual de Fidel Castro y Ernesto Che Guevara y de algunas de las conversaciones que determinaron la creación del premio testimonio por la Casa de las Américas. Se servirá de las herramientas metodológicas desarrolladas en trabajos anteriores (Peris Blanes, 2005, 2008) y en las reflexiones sobre el testimonio latinoamericano de Sklodowska (1992), así como en las reflexiones sobre los debates de los sesenta de Claudia Gilman (2003) y Marcela Croce (2006). Tratará, además, de inscribir el análisis de dichos textos en un contexto de intervenciones más amplio, que indique su rela- 
ción con las condiciones ideológicas y discursivas del momento, de acuerdo a la perspectiva histórica y social del testimonio trazada por Wieviorka (1998, pp. 13):

El testimonio (...), expresa, además de la experiencia individual, el o los discursos que tiene la sociedad, en el momento en que el testigo cuenta su historia, sobre los acontecimientos que el testigo ha vivido. Dice, en principio, lo que cada individuo, cada vida, (...) tiene de irreductiblemente único. Pero lo dice con las palabras que son propias de la época en que testimonia, a partir de un cuestionamiento y de unas expectativas que son también contemporáneas de su testimonio, asignándole finalidades dependientes de intereses políticos o ideológicos, contribuyendo así a crear una o más memorias colectivas, erráticas en su contenido, en su forma, en su función y en la finalidad, explícita o no, que ellas se asignan.

\section{LA POETIZACIÓN DEL IMAGINARIO ANTIINTELECTUAL}

Si en este contexto resultan de interés las canciones de Silvio Rodríguez y la Nueva Trova Cubana es porque éstas construyeron una estructura poética de indudable eficacia en torno a algunos elementos centrales de los debates sobre la función del intelectual de la segunda mitad de los años sesenta. Al tratarse de textos de gran capacidad sintética, lograron absorber y elaborar elementos latentes en ese conflicto cultural, pero que no aparecían conceptualizados como tales en él.

La "Canción para la Columna Juvenil del Centenario"2, escrita en 1967 en el convulso contexto que siguió a la muerte de Che Guevara en Bolivia, se hacía eco de un conflicto de legitimidades que estaba teniendo lugar en el seno de la cultura cubana y latinoamericana de la época: aquel que enfrentaba la legitimidad de la práctica cultural con la de la acción guerrillera.

El texto de la canción se abría con una nítida contraposición entre la vida de la bohemia habanera y la dinámica de la guerrilla en la selva: "Mientras la ciudad / aún a las cuatro está encendida, / sé donde por años la luz es un farol/ y el sueño diversión/ única diversión". De esa contraposición se derivaba otra, de un calado mayor y central en las polémicas intelectuales

\footnotetext{
${ }^{2}$ Por Silvio Rodríguez y Pablo Milanés como miembros del Grupo de Experimentación Sonora (GES). También se conoce la canción como "De una vez", como fue editada en el disco Cuando digo futuro de Silvio Rodríguez.
}

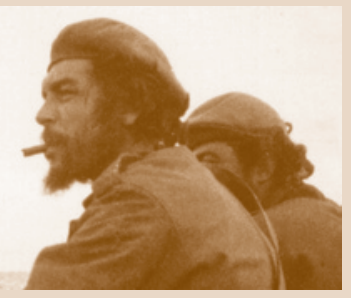

E. Guevara 


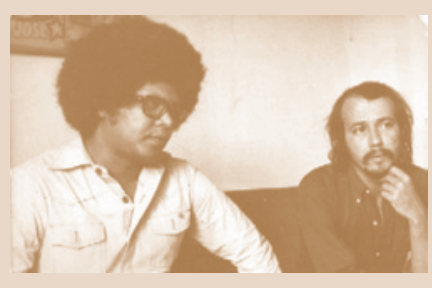

P. Milanés y S. Rodríguez en los años 70 de la época: la que enfrentaba la práctica artística con la lucha guerrillera: "Sé que ahora mismo/ mientras se entona cualquier canto,/ (...) se está luchando allá".

Tras esa introducción dicotómica, Rodríguez y Milanés abrían una sucesión de interrogantes que aludían al valor y al estatuto de la experiencia guerrillera:
¿Qué va a pagar
la sangre que la tierra absorbe?
¿Qué oro que no es oro de sueños pesa así?
¿Qué puede valer más?
¿Qué paga ese sudor, el tiempo que se va?
¿Qué tiempo están pagando, el de su vida?

La imposible respuesta de esas preguntas retóricas aludía al estatuto inconmensurable del acto guerrillero, imposible de ser comparado con otra práctica y capaz de devaluar cualquier otro tipo de intervención. Ante él, parecían decirnos los cantautores, su propio canto carecía de eficacia y de valor.

Ese planteamiento no era, sin embargo, original. Estaba conectado con un imaginario emergente en la cultura cubana (y latinoamericana) que Claudia Gilman ha definido como 'antiintelectualismo' (2003, pp. 143232). Gilman define así el proceso por el cual, en la segunda mitad de los años sesenta, las disputas sobre la función del intelectual en el proyecto revolucionario habían llegado a un estado en que el paradigma del intelectual comprometido, carente de un programa de acción concreto, dejó de servir como paraguas para las diferentes posiciones intelectuales del campo cultural de izquierdas.

En ese contexto, las exigencias de participación revolucionaria a que estuvieron sometidos los agentes de la cultura terminaron por devaluar esa noción de compromiso y desacreditar las competencias específicas del intelectual para intervenir en la sociedad revolucionaria (Gilman, 2003, pp. 160). Puede decirse, pues, que el paso del paradigma del 'intelectual comprometido' al del 'intelectual revolucionario' estuvo marcado por una pérdida de confianza en las competencias profesionales del escritor y en la necesidad de que éste se entregara a la acción revolucionaria en otros ámbitos diferentes al cultural.

La canción de Rodríguez y Milanés era, a este respecto, profundamente paradójica -como lo eran, por otra parte, muchos de los textos del periodo- ya que daba cuenta de esa devaluación de la práctica intelectual me- 
diante una sucesión de imágenes de gran densidad poética. Se servía, pues, de las mismas competencias cuyo valor estaba cuestionando. El cierre de "Canción para la Columna..." condensaba de un modo altamente sugerente esa posición antiintelectualista: ante la imposibilidad de responder a los diferentes interrogantes retóricos que abría la experiencia inconmensurable de la guerrilla, la única respuesta posible era el enmudecimiento del intelectual:

Cuando a las once el sol parte al centro del horror cuando consignas y metas piden su paredón, cuando de oscuro a oscuro conversan con la acción, la palabra es de ustedes, me callo por pudor.

El último verso, que se repetía hasta siete veces al final de la canción, daba un cierre perfecto al imaginario antiintelectualista: el enmudecimiento voluntario del cantante/escritor se veía acompañado por la cesión de su lugar de enunciación ("la palabra es de ustedes") a los protagonistas de la acción guerrillera. Al cederles la voz a los guerrilleros, sin embargo, Rodríguez y Milanés incurrían en una cierta ambivalencia, ya que no quedaba claro si aludían al tópico de que los guerrilleros 'hablaban' a través de sus acciones ("conversan con la acción"), o si ciertamente estaban invitándolos a tomar la palabra y a narrar, desde su propio punto de vista, esa experiencia que carecía de parangón en la cultura cubana.

\section{EL TESTIMONIO COMO RESPUESTA}

La canción "Playa Girón", escrita dos años más tarde, resolvería esa ambigüedad de modo contundente. Si "Canción para la Columna..." se hacía eco del conflicto de legitimidades entre la práctica cultural y la acción guerrillera, "Playa Girón"3 enunciaba detalladamente el conflicto del escritor de voluntad revolucionaria e incorporaba, para ello, algunas de las disyuntivas y significantes centrales del debate que, cada vez con más virulencia, estaban cercando la labor del escritor de izquierdas latinoamericano.

\footnotetext{
${ }^{3}$ La canción hacía referencia a la labor de los marineros del barco 'Playa Girón', en el que el propio Rodríguez había faenado durante un tiempo, pero su nombre le permitía aludir, de forma tangencial, al gran mito de la resistencia revolucionaria cubana, ya que Playa Girón fue el lugar en el que el ejército de Castro repelió el intento de invasión militar de la isla de soldados entrenados y comandados por la CIA.
} 


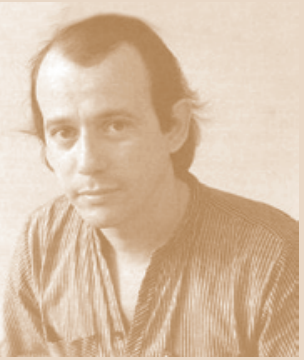

S. Rodríguez
Rodríguez daba estructura y coherencia poética a una pregunta que muchos de los escritores del periodo se estaban haciendo en esos momentos y que podríamos formular así: ¿¿cómo hablar de un tema revolucionario sin incurrir en los 'pecados' del escritor/intelectual tal como estaban siendo denunciados en el debate público de la época? Ante esa pregunta, la escritura se veía atrapada en un sistema múltiple de prohibiciones, efecto de la rigurosa autovigilancia que atenazó al campo literario y cultural en la segunda mitad de los años sesenta (Gilman, 2003, p. 167).

Compañeros poetas
tomando en cuenta los últimos sucesos
en la poesía, quisiera preguntar
me urge,
¿qué tipo de adjetivos se deben usar
para hacer el poema de un barco
sin que se haga sentimental,
fuera de la vanguardia
o evidente panfleto,
si debo usar palabras
como Flota Cubana de Pesca
y'Playa Girón'?

Tal como se planteaba en la canción, la autovigilancia política y estética a la que debía someterse el escritor hacía imposible una escritura positiva. Ante la red de prohibiciones que de ella se derivaba, la única productividad viable del intelectual parecía ser describir su propia incapacidad de expresión. Al igual que en "Canción para la Columna...", Rodríguez recurría paradójicamente a procedimientos marcadamente literarios para describir esa incapacidad de escritura, extendiéndola, además, a los ámbitos de la música y de la historia ${ }^{4}$.

El final de la canción, sin embargo, ofrecía una salida bastante concreta a esa incapacidad, que hacía explícito el giro que ya había apuntado al final de "Canción para la Columna...". Ante la imposibilidad del cantante/poeta de resolver por sí mismo los problemas que ese sistema de límites y prohibiciones le imponía, optaba de nuevo por abandonar su lugar de enuncia-

\footnotetext{
4 "Compañeros de música, / tomando en cuenta esas politonales / y audaces canciones, quisiera preguntar / me urge, / ¿qué tipo de armonía se debe usar / para hacer la canción de este barco / con hombres de poca niñez (...) Compañeros de historia, / tomando en cuenta lo implacable / que debe ser la verdad, quisiera preguntar / me urge tanto, /¿qué debiera decir, qué fronteras debo respetar?"
} 
ción y cederlo a otros agentes sociales. Narrar la historia de ese episodio revolucionario, parecía decirnos la canción, resultaba imposible desde la posición intelectual del hombre de cultura, y sólo sería posible desde la voz y la posición social de aquellos que lo habían vivido: "que escriban pues la historia/ su historia / los hombres / del 'Playa Girón”".

Lo importante de este giro final es que añadía un elemento más al conflicto de legitimidades entre la práctica cultural y la lucha armada que estaba teniendo lugar en el campo cultural cubano: la acción no sólo tenía más valor que la palabra sino que, además, podía legitimar lugares de enunciación nuevos, que las culturas prerrevolucionarias no habían previsto.

\section{EL TESTIMONIO Y LA CRÍTICA A LOS INTELECTUALES}

Lo que las canciones de Silvio Rodríguez apuntaban era, ni más ni menos, que un nuevo tipo de enunciación de corte testimonial debía aparecer para resolver las contradicciones estéticas, políticas y sociales a las que se enfrentaban los intelectuales de la época en un momento de descrédito de sus competencias profesionales específicas. En ese sentido, Rodríguez hacía explícita, en un momento de máximo auge del imaginario antiintelectual, una idea que había sobrevolado los debates y las polémicas sobre la función del escritor revolucionario, pero que lo había hecho de forma implícita, carente de una conceptualización clara.

Hasta casi el final de la década de los sesenta, las Palabras a los intelectuales con que Fidel Castro había intervenido en el congreso de pedagogía de 1961, sirvieron de guía y referente fundamental para la práctica intelectual de los 'amigos de la Revolución'. En ellas, y ante el extendido temor de que el Estado atentara contra la libertad de expresión, Castro marcaba los límites a los intelectuales que deseaban vincular su trabajo al devenir de la Revolución. Lo hacía a través de una hábil retórica de la cual no podían derivarse directrices ni programas estéticos concretos, sino solamente la preeminencia del carácter revolucionario sobre cualquier otra consideración. Las palabras son bien conocidas:

Creo que esto es bien claro. ¿Cuáles son los derechos de los escritores y de los artistas revolucionarios o no revolucionarios? Dentro de la Revolución: todo; contra la Revolución ningún derecho (...) ¿Quiere decir que vamos a decir aquí a la gente lo que tiene que escribir? No. Que cada cual escriba lo que quiera, y si lo que escribe no sirve, allá él. Si lo que pinta no sirve, allá él... 


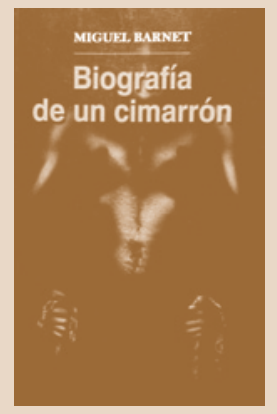

Menos citado es el hecho de que ese señalamiento de los límites que los intelectuales no debían traspasar estuvo acompañado de la representación imaginaria de un nuevo tipo de actividad cultural, resultado potencial del proceso revolucionario. Una actividad cultural en la que los intelectuales habrían cedido su lugar de privilegio a un sujeto popular que, como efecto de las políticas pedagógico-culturales de la revolución, sería capaz de narrar su propia historia mejor que ningún otro actor social.

En días recientes nosotros tuvimos la experiencia de encontrarnos con una anciana de 106 años que había acabado de aprender a leer y escribir y nosotros le propusimos que escribiera un libro. Había sido esclava y nosotros queríamos saber cómo un esclavo vio el mundo cuando era esclavo, cuáles fueron sus primeras impresiones de la vida, de sus amos, de sus compañeros. Creo que esta vieja puede escribir una cosa tan interesante como ninguno de nosotros podríamos escribirla sobre su época y es posible que en un año se alfabetice y además escriba un libro a los 106 años. ¡Esas son las cosas de las revoluciones! ¿Quién puede escribir mejor que ella lo que vivió el esclavo?

Como en otras intervenciones de la época, el testimonio no aparecía conceptualizado como tal. Se trata, de hecho, de un discurso que antecede en 5 años a la publicación del texto fundacional de Miguel Barnet Biografía de un cimarrón (1966). Sin embargo, en las palabras de Castro aparece claramente delineada la idea de una producción simbólica liberada de la figura del intelectual y cuya enunciación fuera responsabilidad de un sujeto popular capaz de hacerse cargo de ella.

Lo importante no es solamente la emergencia de esa idea que, como se sabe, desempeñaría en el futuro un rol fundamental en la evolución de la literatura latinoamericana (Sklodowska, 1992) sino también la función que la invocación a esa idea tenía en el discurso de Castro. La representación de ese potencial sujeto de la cultura revolucionaria tenía lugar, de hecho, en el contexto de una crítica a la posición del intelectual, en el momento en que el jefe del Estado marcaba por primera vez los límites de la actividad de los intelectuales.

Por ello podemos sugerir que esa invocación seminal -y no conceptualizada como tal- de la enunciación testimonial como eje de la nueva cultura cumplía una función de 'advertencia' al campo intelectual, dado que señalaba una práctica cultural potencial en que las competencias específicas de los intelectuales habrían perdido su razón de ser. Se trataba, pues, de un primer momento del conflicto que, años más tarde, enfrentaría al Estado 
cubano a una parte importante de la intelectualidad latinoamericana que hasta entonces había estado ligada a la Revolución (Croce, 2006, pp. 205280).

\section{EL HOMBRE NUEVO Y LA SUPERACIÓN DE LA INTELECTUALIDAD PERVERTIDA}

En 1965, Ernesto ‘Che’ Guevara había enviado un artículo a la redacción del semanario Marcha que habría de convertirse en un referente fundamental de la teoría política revolucionaria y de las reflexiones sobre el lugar de la cultura en ella. En ese artículo Guevara acuñaba su famoso concepto del 'Hombre Nuevo': el objeto de la Revolución no era la toma de poder político, sino la producción de una nueva calidad de la subjetividad. La dinámica guerrillera y las transformaciones sociales de la Revolución debían, pues, encaminarse a la creación de sujetos nuevos con valores diferentes a los de las sociedades burguesas, individualistas y capitalistas que la habían precedido.

En ese contexto, Guevara señalaba la incapacidad de los intelectuales para integrarse al proceso revolucionario, dado que llevaban consigo los valores de la sociedad prerrevolucionaria de la que era efecto la propia idea de 'intelectual':

la culpabilidad de muchos de nuestros intelectuales y artistas reside en su pecado original; no son auténticamente revolucionarios. Podemos intentar injertar el olmo para que dé peras; pero simultáneamente hay que sembrar perales. Las nuevas generaciones vendrán libres del pecado original. Las probabilidades de que surjan artistas excepcionales serán tanto mayores cuanto más se haya ensanchado el campo de la cultura y la posibilidad de expresión. Nuestra tarea consiste en impedir que la generación actual, dislocada por sus conflictos, se pervierta y pervierta a las nuevas (Guevara [1965] 1981, p. 530).

Así pues, Guevara señalaba la necesidad de contar con los intelectuales para llevar a cabo su proyecto de extensión cultural, pero dejaba la puerta abierta a que, en un segundo momento, los intelectuales desaparecieran como tales para ceder su lugar a las generaciones futuras, 'libres del pecado original'. Es decir, los intelectuales debían ayudar a producir las condiciones para su propia desaparición como sujetos de una práctica simbólica 
específica ${ }^{5}$ para la emergencia de un nuevo tipo de cultura popular y revolucionaria.

En coherencia con lo anterior, Guevara repudiaba las manifestaciones culturales del pasado por expresar valores prerrevolucionarios y hacía blanco de sus críticas explícitas tanto al realismo socialista de origen soviético como a la vanguardia de inspiración europea, terciando en un debate que, en los años anteriores, había tenido a estas dos corrientes estéticas como elementos centrales de discusión ${ }^{6}$.

Esa asociación de la idea del intelectual a la herencia de los valores prerevolucionarios que debían extirparse de la nueva sociedad no decía, sin embargo, cuáles iban a ser las figuras sociales que sustituirían a los intelectuales en la sociedad futura. Con todo, apuntaba algunas pistas sobre ello:

Falta el desarrollo de un mecanismo ideológico-cultural que permita la investigación y desbroce la mala hierba (...) la necesidad de la creación del hombre nuevo, que no sea el que representa las ideas del siglo XIX, pero tampoco las de nuestro siglo decadente y morboso. El hombre del siglo XXI es el que debemos crear, aunque todavía es una aspiración subjetiva y no sistematizada. (...) Ya vendrán los revolucionarios que entonen el canto del hombre nuevo con la auténtica voz del pueblo (Guevara [1965] 1981, p. 530).

La última frase, excesivamente retórica y muy vaga en su definición, abría una línea de fuga hacia los agentes culturales del futuro que habrían de sustituir a los intelectuales de la actualidad. De ellos se nos decía que serían revolucionarios, que cantarían al hombre nuevo y que su voz sería la del pueblo. Su imagen, aunque vaga, se recortaba sobre el negativo del intelectual, carente de espíritu revolucionario y distanciado socialmente del pueblo.

Como el texto anteriormente citado de Fidel Castro, el artículo de Guevara anudaba a su crítica a los intelectuales la representación de una práctica cultural futura en la que el sujeto de enunciación debía confundirse con

\footnotetext{
${ }^{5}$ Por ello Claudia Gilman hace referencia al 'mito de la transición' del intelectual revolucionario, magníficamente ejemplificado en el poema de Roberto Fernández Retamar "Tenía usted razón, Tallet, somos hombres de transición".

6 "Se busca entonces la simplificación, o lo que entiende todo el mundo, que es lo que entienden los funcionarios. Se anula la auténtica investigación artística y se reduce el problema de la cultura general a una apropiación del presente socialista y del pasado muerto (por tanto, no peligroso). Así nace el realismo socialista sobre las bases del arte del pasado. No se puede oponer al realismo socialista 'la libertad', porque ésta no existe todavía, no existirá hasta el completo desarrollo de la sociedad nueva" (Guevara [1965] 1981, p. 530).
} 
el pueblo del que, según ellos mismos, los intelectuales estaban excluidos. Con el tiempo, y siguiendo el ejemplo de los textos de Guevara y Castro, los múltiples discursos que trataron de criticar, poner límites y cuestionar la credibilidad del rol social de los intelectuales, incorporaron sistemáticamente la representación difusa de esa práctica cultural potencial. Se trataba de un elemento poco definido al que se aludía constantemente, pero sin demasiada concreción, y que con el tiempo llegó a adquirir una función importante en los debates sobre la función del intelectual.

De hecho, las críticas a la figura social del intelectual y a la validez de sus competencias profesionales específicas se irían gramaticalizando en un breve periodo de tiempo, hasta adquirir una sintaxis más o menos reconocible y recurrente, que es la que Silvio Rodríguez elaboró poéticamente en las canciones analizadas arriba. En ella, la alusión a esa práctica cultural futura en la que el sujeto de enunciación se confundiría con la voz del pueblo sirvió para marcar los límites a la función del intelectual y para 'advertirle' de que la cultura revolucionaria no necesitaba al intelectual para desarrollarse.

Aunque careciera de concreción práctica, la invocación continuada y ritual de esa práctica cultural futura enunciada en la voz del pueblo desempeñó una función de gran importancia en la crítica a la función del intelectual y, por tanto, en los debates públicos que Gilman ha descrito como los del auge del antiintelectualismo (Gilman, 2003, pp. 189-232).

\section{LA EMERGENCIA DEL TESTIMONIO}

Con el tiempo, la categoría novedosa del testimonio vino a abrochar y dar una función más clara a ese elemento imaginario que hasta entonces había carecido de una adecuada conceptualización, aunque estuviera siempre latente en las polémicas y debates sobre la función del intelectual revolucionario, como las canciones de Silvio Rodríguez demuestran. No se trata, entiéndase bien, de que la emergencia de los textos testimoniales supusiera el advenimiento de esa nueva forma de cultura, sino de que la idea y la etiqueta de testimonio permitió asociar prácticas simbólicas muy diversas a esa función argumentativa que había servido para poner límites a la autoridad de los intelectuales. Podríamos decir, incluso, que la categoría de testimonio vino a llenar una función sintáctica de la crítica al intelectual liberal que llevaba funcionando desde hacía años.

En 1970 la institución cultural más importante de Cuba, la Casa de las Américas, incorporó la categoría de testimonio a sus premios literarios, en 
uno de los momentos más álgidos de la polémica sobre la función del intelectual en el proceso revolucionario, que estallaría definitivamente al año siguiente con el conocido 'caso Padilla', que enfrentó a numerosos escritores de izquierdas al régimen de Castro que hasta entonces habían apoyado (Croce, 2008, pp. 205-280)7. Tal como señala George Yúdice:

Es significativo que se introdujera el premio justamente cuando el 'endurecimiento' de la línea soviética del gobierno cubano produjo una ruptura con los intelectuales latinoamericanos liberales. Esta fue, claramente, la maniobra contestataria y positiva de los cubanos en el sentido de que ayudó a socavar al 'boom', con su culto de autorreferencialidad, simulacro y escritura posestructuralista (Yúdice, 1991, p. 26).

En ese contexto de máxima tensión cultural, la creación del nuevo premio servía para reconocer y dar legitimidad a diversos tipos de escritura que, bajo el cuño de la no-ficción, habían hecho acto de emergencia en los años anteriores y carecían, hasta el momento, de una conceptualización en el circuito editorial y crítico. Pero también para dar cuerpo a ese espacio difuso que había planeado en las intervenciones políticas que trataban de poner límites a la actuación del intelectual en el proceso revolucionario y que, bajo la idea abstracta de un sujeto de enunciación popular, advertía a los intelectuales de su prescindibilidad futura. Si las polémicas de los sesenta se habían estructurado, como se ha dicho, sobre el conflicto de legitimidades entre la práctica intelectual y la acción guerrillera, no sorprende que el primer texto premiado en la categoría de testimonio fuera, precisamente, La guerrilla tupamara, de Maria Esther Gilio.

En las conversaciones en que se decidió la creación del premio testimonio se podían detectar algunas de las preocupaciones de aquellos intelectuales 'de transición' que luchaban por conceptuar adecuadamente los procesos culturales que estaban viviendo:

Los géneros que tenemos aquí no corresponden más al estado actual de la literatura, como existe. Porque excluye de manera bastante terminante muchos géneros como el reportaje, el testimonio, la factografía, la novela no-ficción (Hans Magnus Enzensberger, en VVAA, 1995, p. 123).

\footnotetext{
${ }^{7}$ De la Nuez ha analizado el efecto de imán que la Revolución cubana tuvo sobre los intelectuales de izquierda de la época (2006).
} 
Enzensberger señalaba la ausencia de una categoría crítico-editorial capaz de dar cuenta de la multiplicidad y diversidad de textos no ficcionales publicados en los años anteriores. De ese modo, resaltaba la incapacidad del campo intelectual para detectar los movimientos de una cultura que, en sus rasgos mayores, ya no hallaba en los intelectuales profesionales a sus actores principales. Esa creciente percepción intelectual de que sus competencias estaban siendo desplazadas por otros actores sociales se verificaba, asimismo, en la indeterminación de los criterios con que los intelectuales ligados a Casa de las Américas juzgaron esas nuevas escrituras que iban a encuadrarse en la categoría de testimonio:

Existen, entre otras, buenas obras literarias, con interés, que no todas llegan a la calidad de un premio que podríamos mencionar, pero cuyo valor no está solamente en lo literario, sino en lo que testimonian del proceso de la América Latina. (...) Eso me dice que en la América Latina, aunque no se esté premiando una hermosa obra -porque cualquier obra hermosa contribuye al mejoramiento de todos, y al desarrollo de nuestro pueblo-, esa obra es un testimonio del proceso histórico del cual soy partícipe (Ángel Rama, en VVAA, 1995, p. 123).

Rama abordaba el testimonio basculando entre diferentes paradigmas de valoración heterogéneos entre sí, demostrando una cierta indefinición en los criterios con que estas obras nuevas podrían ser valoradas. Viniendo de uno de los intelectuales más lúcidos de la época, esa indeterminación era el síntoma de una cierta pérdida de referencias, que la incorporación de los textos testimoniales a la categoría de literatura no hacía sino profundizar.

Las contradicciones de una intelectualidad escindida por su empatía política hacia esas nuevas formas culturales que excluían, sin embargo, todo lo que ella representaba, determinaron el modo en que se presentó el nuevo premio. Quizás fuera ello lo que llevó a Manuel Galich, encargado de redactar las bases del concurso en 1970, a definirla institucionalmente en términos puramente negativos (1995, pp. 124-125), basándose únicamente en lo que el testimonio se diferenciaba del reportaje, de la narrativa, de la investigación o de la biografía.

En realidad, las diferencias resaltadas eran tan de matiz que el testimonio aparecía como una nueva categoría que incluía todas las anteriores y permitía asociarlas al paradigma de lo literario del que hasta entonces habían estado excluidas. El único elemento específico del nuevo género era la presencia constante de un componente fuertemente político y enraiza- 
do en las luchas sociales del presente ${ }^{8}$. Pero esa orientación marcadamente política tenía el peligro, para los intelectuales responsables del premio, de que se soslayaran los valores estéticos a la hora de valorarlos. Fue por ello que durante años se incluyó en las bases del concurso, tras explicarse lo que se entendía por testimonio, la siguiente aclaración: "la forma queda a discreción del autor, pero la calidad literaria también es indispensable" (Jorge Fornet, 1995, p. 121): por supuesto que esa 'calidad literaria' quedaba fuera de toda definición normativa.

Ese giro no sólo revelaba los diferentes paradigmas de valoración que los textos testimoniales iban a convocar, sino también la incapacidad de la institución cultural y de sus intelectuales para liberar a las nuevas categorías de los elementos con los que tradicionalmente se había juzgado la literatura. Tal como Guevara anunciaba en su texto sobre el hombre nuevo, los representantes de la intelectualidad intentaban poner sus propios límites (la idea 'elitista' de 'calidad literaria', por ejemplo) a las nuevas narrativas populares. Desde un punto de vista antiintelectualista, ello era bastante lógico: no era de extrañar que los intelectuales recurrieran a la misma idea que estas escrituras hacían entrar en crisis (las competencias profesionales del escritor) para poner límites a la crítica implícita del intelectual que les acompañaba.

\section{CONCLUSIONES}

La emergencia y consolidación de la categoría de testimonio estuvo, pues, ligada a la crítica al intelectual liberal y, por tanto, no puede desligarse de las polémicas y debates sobre la función del intelectual en la Revolución que tuvieron lugar en los años sesenta en Cuba. De hecho, y tal como se ha mostrado en este artículo, la crítica al campo intelectual por parte de los dirigentes revolucionarios incluyó recurrentemente una alusión a una práctica cultural imaginaria que tendría como agente al sujeto popular de la Revolución, al Hombre Nuevo que ésta había de generar. Las canciones de Silvio Rodríguez de finales de los años sesenta no hacían sino absorber

\footnotetext{
8 "En el testimonio, lo biográfico de uno o varios sujetos de indagación debe ubicarse dentro de un contexto social, estar íntimamente ligado a él, tipificar un fenómeno colectivo, una clase, una época, un proceso (una dinámica) o un no proceso (un estancamiento, un atraso) de la sociedad o de un grupo o capa característicos, siempre que, por otra parte, sea actual, vigente, dentro de la problemática latinoamericana” (Galich, 1995: 125).
} 
los componentes de esa crítica, que con el tiempo había ido gramaticalizándose, y darles una estructura poética de gran eficacia.

La categoría de 'testimonio' reconoció culturalmente textos muy diversos, pero sobre todo vino a abrochar y a dar consistencia y densidad a ese espacio confuso y carente de conceptualización, que desempeñaba una función sintáctica importante en la crítica al intelectual liberal. Sirvió, por tanto, para dar apoyo al imaginario antiintelectualista que se había instalado en las instituciones culturales cubanas, en un periodo en el que las polémicas sobre la función del intelectual estaban alcanzando un punto extremo de virulencia del que la 'familia intelectual latinoamericana' no se recuperaría nunca.

Quedaría por analizar, y a esta cuestión deberán consagrarse futuras investigaciones, cómo respondieron los textos testimoniales a las directrices contradictorias que emanaron de los debates y polémicas sobre el rol de los intelectuales ante la revolución. También las estrategias de los escritores identificados con la posición intelectual que desacreditaba el antiintelectualismo pero que, sin embargo, no rompieron con la Revolución tras el estallido del 'caso Padilla' y debieron inscribir sus prácticas narrativas y culturales en el sistema de restricciones y límites que, desde dentro, había descrito con sutileza y singular poética Silvio Rodríguez en 'Playa Girón'.

\section{REFERENCIAS}

Castro, F. (1961). "Palabras a los intelectuales". En: www.granma.cubaweb.cu

Croce, M. (ed.) (2006). Polémicas intelectuales en América Latina. Del 'meridiano intelectual' al caso Padilla (1927-1971). Buenos Aires, Argentina: Simurg.

De la Nuez, I. (2006). Fantasía roja. Los intelectuales de izquierdas y la revolución cubana. Barcelona, España: Debate.

Fornet, J. (1995). "La Casa de las Américas y la 'creación' del género testimonio". Casa de las Américas 200, 120-121.

Galich, M. (1995). "Para una definición del género testimonio". Casa de las Américas 200, 124-125.

Gilman, C. (2003). Entre la pluma y el fusil. Debates y dilemas del escritor revolucionario en América Latina. Buenos Aires, Argentina: Siglo XXI.

Grupo de Experimentación Sonora (Silvio Rodríguez y Pablo Milanés) (1967). "Canción para la Columna Juvenil del Centenario". La Habana, Cuba: Producciones ICAIC.

Guevara, E. [1965] (1981). "El socialismo y el hombre en Cuba" en Edmundo Desnoes. Los dispositivos en la flor. Cuba: literatura desde la revolución, pp. 525-532, Hanover, Alemania: Ediciones del Norte.

Peris Blanes, J. (2005). La imposible voz. Memoria y representación de los campos 
de concentración en Chile: la posición del testigo. Santiago de Chile: Cuarto Propio.

Peris Blanes, J. (2008). Historia del testimonio chileno. De las estrategias de denuncia a las políticas de memoria. Valencia: Quaderns de Filologia.

Rodríguez, S. [1969] (1975). "Playa Girón”. Días y flores. La Habana, Cuba: EGREM.

Sklodowska, E. (1992). Testimonio hispano-americano. Historia, teoría, poética. Nueva York, Estados Unidos: Peter Lang.

VV.AA. (1995). "Conversación en torno al testimonio". Casa de las Américas 200, $122-124$.

Wieviorka, A. (1998). L'ère du témoin. Paris, Francia: Plon.

Yúdice, G. (1991). “Testimonio and postmodernism”. En: Voices of the voiceless in testimonial literatures. (Gudelberger y Kearney, eds.) número especial de Latin American Perspectives 18.3, 15-31. 